\title{
Risk factors of uncontrolled hypertension in urban slums of Central India : A Community health worker based two-year follow up
}

Abhijit P Pakhare ${ }^{1}$, Anuja Lahiri, Neelesh Shrivastava ${ }^{2}$, Subba Krishna ${ }^{1}$, Ankur Joshi ${ }^{1}$, Shubham $\mathrm{Atal}^{3}$, Sagar Khadanga, Rajnish Joshi ${ }^{4 \$}$

\section{Affiliations and Institutions}

\begin{tabular}{|l|l|l|l|}
\hline No & Name & Affiliation & Email \\
\hline 1 & $\begin{array}{l}\text { Abhijit P } \\
\text { Pakhare }\end{array}$ & $\begin{array}{l}\text { Department of Community and } \\
\text { Family Medicine, All India Institute } \\
\text { of Medical Sciences, Bhopal }\end{array}$ & abhijit.cfm@aiimsbhopal.edu.in \\
\hline 1 & $\begin{array}{l}\text { Anuja } \\
\text { Lahiri }\end{array}$ & $\begin{array}{l}\text { Department of Community and } \\
\text { Family Medicine, All India Institute } \\
\text { of Medical Sciences, Bhopal }\end{array}$ & anuja.ds@ aiimsbhopal.edu.in \\
\hline 2 & $\begin{array}{l}\text { Neelesh } \\
\text { Shrivastava }\end{array}$ & $\begin{array}{l}\text { NCD Urban Project, Department of } \\
\text { Medicine, All India Institute of } \\
\text { Medical Sciences, Bhopal }\end{array}$ & neeleshstv@ gmail.com \\
\hline 1 & $\begin{array}{l}\text { Subba } \\
\text { Krishna N }\end{array}$ & $\begin{array}{l}\text { Department of Community and } \\
\text { Family Medicine, All India Institute } \\
\text { of Medical Sciences, Bhopal }\end{array}$ & krish.haritsa@ gmail.com \\
\hline 1 & $\begin{array}{l}\text { Ankur Joshi } \\
\text { Department of Community and } \\
\text { Family Medicine, All India Institute } \\
\text { of Medical Sciences, Bhopal }\end{array}$ & ankur.cfm@aiimsbhopal.edu.in \\
\hline 3 & $\begin{array}{l}\text { Shubham } \\
\text { Atal }\end{array}$ & $\begin{array}{l}\text { Department of Pharmacology, All } \\
\text { India Institute of Medical Sciences, } \\
\text { Bhopal }\end{array}$ & Shubham.pharma@aiimsbhopal.edu.in \\
\hline 4 & $\begin{array}{l}\text { Sagar } \\
\text { Khadanga }\end{array}$ & $\begin{array}{l}\text { Department of Medicine, All India } \\
\text { Institute of Medical Sciences, Bhopal }\end{array}$ & sagar.genmed@aiimsbhopal.edu.in \\
\hline $4 \$$ & $\begin{array}{l}\text { Rajnish } \\
\text { Joshi }\end{array}$ & $\begin{array}{l}\text { Department of Medicine, All India } \\
\text { Institute of Medical Sciences, Bhopal }\end{array}$ & rajnish.genmed@ aiimsbhopal.edu.in \\
\hline
\end{tabular}

Author Email

\$Corresponding Author-

Dr Rajnish Joshi

Department of Medicine, All India Institute of Medical Sciences, Bhopal

Email- rajnish.genmed@aiimsbhopal.edu.in

Word Count-

Abstract- 269

Main Text- 3101

No. of Tables- $3+$ Supplementary Tables-2

No. of Figures- 2 


\title{
Risk factors of uncontrolled hypertension in urban slums of Central India : A Community health worker based two-year follow up
}

\begin{abstract}
Background: Hypertension is a leading cause of cardiovascular diseases its control is poor. There exists heterogeneity in levels of blood-pressure control among various population subgroups. Present study conducted in framework of National Program for prevention and control of cancer, diabetes, cardiovascular diseases and stroke (NPCDCS) in India, aims to estimate proportion of optimal blood pressure control and identify potential risk factors pertaining uncontrolled hypertension consequent to initial screening.
\end{abstract}

Methods: We conceived a cohort of individuals with hypertension confirmed in a baseline screening in sixteen urban slum clusters of Bhopal (2017-2018). Sixteen Accredited Social Health Activists (ASHAs) were trained from within these urban slum communities. Individuals with hypertension were linked to primary care providers and followed-up for next two years. Obtaining optimal blood-pressure control (defined as SBP $<140$ and $\mathrm{DBP}<90 \mathrm{~mm}$ of $\mathrm{Hg}$ ) was a key outcome. Role of baseline anthropometric, and CVD risk factors was evaluated as predictors of blood-pressure control on univariate and multivariate analysis.

Results: Of a total of 6174 individuals, 1571 (25.4\%) had hypertension, of which 813 were previously known and 758 were newly detected during baseline survey. Two year follow up was completed for 1177 (74.9\%). Blood-pressure was optimally controlled in 301 (26\%) at baseline, and in 442 (38\%) individuals at two years (absolute increase of 12\%; 95\% CI 10.213.9). Older age, physical-inactivity, higher BMI and newly diagnosed hypertension were significantly associated with uncontrolled blood-pressure.

Conclusions: In the current study we found about six of every ten individuals with hypertension were on-treatment, and about four were optimally controlled. These findings provide a benchmark for NPCDCS, in terms of achievable goals within short periods of follow-up.

Key words: hypertension, optimal blood pressure control, community health worker, physical inactivity 


\section{Risk factors of uncontrolled hypertension in urban slums of Central India : A Community health worker based two-year follow up}

\section{Introduction}

Hypertension is a leading cause of cardiovascular diseases and in India its control is poor. Among those with hypertension, in urban India less than half are aware of their elevated blood pressure, and only one in five individuals are controlled. The estimates in rural areas are worse, with only onefourths being aware, and one in ten individuals controlled. ${ }^{1}$ Previous studies by our group have estimated prevalence of hypertension and other cardiovascular risk factors in state wide representative survey of Madhya Pradesh. We found that $22.3 \%$ of all individuals had hypertension, but only $11.8 \%$ were on some medication. ${ }^{2,3}$ The proportion of those controlled is likely to be only about half of those on medication. In order to improve control, availability and access to quality health-care is imperative, in order to reduce cardiovascular mortality and morbidity. ${ }^{4}$ Pathway for effective blood pressure control requires individuals to be "screened"; all screened individuals who have elevated blood pressure must be "aware" of their status; all those who are aware need to get "treated"; and all those treated should be "controlled". There occurs a loss of numbers at each of these screeningawareness-treatment-control pathway the corresponding numbers in a recent systematic review of studies from India were $76 \%, 44 \%, 13 \%$ and $8 \%$ respectively. ${ }^{5}$ Belonging to male gender, living in a rural area, being poor, and single are considered as factors associated with such a loss in numbers at each step in this study. ${ }^{5}$

Once diagnosis of hypertension is made, untreated and uncontrolled hypertension becomes a significant and challenging concern. ${ }^{6}$ There are numerous implementation challenges, especially with lowered target blood pressure goals. A successful blood pressure control model would require a team based approach at primary care level, with a focus on improved adherence supported achieved by improved self-management at patient level, supported by the health system. ${ }^{7}$ Health system is expected to provide improved access to medications, and health awareness in the communities. Various engagement strategies have been used in the last decade, including but not limited to mobilehealth applications ${ }^{8}$, telemedicine services ${ }^{9}$, using fixed dose combinations, and community health worker (CHW) based engagement strategies. ${ }^{10}$ Previous cluster-randomized trials of $\mathrm{CHW}$ based adherence promotion and blood pressure control strategies have demonstrated feasibility of such interventions. While some population based studies have had a limited impact on blood-pressure levels, ${ }^{11,12}$ other facility based studies have shown larger benefits. ${ }^{13,14}$ Clusters where more members have uncontrolled hypertension at baseline, with a higher baseline blood-pressure, have reported greater and more significant reductions. ${ }^{15}$ Even amongst a homogenous health-system, heterogeneity in blood pressure control exists, attributable to better patient engagement. ${ }^{16}$ These findings suggest that some population subgroups, have low health system or CHW engagement levels, and are likely to 
be at a higher risk of uncontrolled blood-pressure. It is important to identify such high-risk population subgroups, so that more focussed strategies can be designed for them.

National Program for prevention and control of cancer, diabetes, cardiovascular diseases and stroke (NPCDCS) in India recommends annual hypertension screening for all adults, and proportion of optimally controlled individuals as a facility level indicator. Once screened, the program recommends CHWs to engage with communities, so as to improve linkages of individuals with hypertension to the primary-care facilities. Once the screening and awareness gap is bridged, the proportion of individuals with hypertension that access primary care facilities and those who are controlled is likely to multiply. Aim of the current study is to identify risk-factors for uncontrolled hypertension, subsequent to initial screening, as envisaged in NPCDCS. The findings would be useful in understanding of long-term challenges in blood-pressure control, and designing of their mitigation strategies.

\section{Methods}

Design and Ethics Statement: We designed a cohort study to answer our research question. The study design was approved by the Institutional human ethics committee (IHEC-LOP/2017/EF00045). All the participants provided a written informed consent for the study related procedures.

Setting: The study was conducted in 16 urban slum clusters of Bhopal, a city with population of about 18 Lakhs, located in central India. A baseline door-to-door survey was conducted in the urban slum clusters between November 2017 and March 2018, details of which are provided elsewhere. ${ }^{17}$ Briefly, all consenting non-pregnant adults above the age of 30 years formed a cross-section, in whom cardiovascular disease (CVD) risk assessment was performed by Accredited social health activists (ASHAs), who are CHWs in these communities. Study supervisors provided oversight, and also confirmed key variables, before stratifying individuals as high risk. Individuals identified at a high CVD risk, especially those with hypertension and diabetes were sought to be linked to urban primary health centres (UPHCs) which are primary-care public-health facilities in these communities. All participants were however free to seek care from alternate private-providers of their choice. Limited generic anti-hypertensive drugs (Amlodipine, Losartan, and Hydrochlorothiazide) are available at nocost from UPHCs with a prescription refill duration varying from 2-4 weeks. Participants who visit primary-care providers usually incur out-of-pocket expenditure for their drug therapy, with a refill duration dependent on their capacity to pay.

Participants: Cohort of individuals with hypertension(either a previously known or a newly detected hypertension), was identified from within the base-line cross-section. During the baseline survey, individuals who reported themselves as diagnosed to have hypertension in the past, were defined as having previously known-hypertension. We also screened for hypertension as part of baseline assessment. ASHAs obtained a first-set of blood-pressure values using a digital sphygmomanometer 
(Omron digital apparatus, Model 7200, Kyoto, Japan) at home of the participants. All the blood pressure readings were then confirmed in a second set of readings obtained by the study supervisor, using the same device. Each set of blood-pressure readings consisted of an average of three values, obtained one-minute apart, using a standardized technique. A person was defined as a newly detected hypertensive, if the blood pressure values were above Systolic blood pressure (SBP) of $140 \mathrm{~mm} \mathrm{Hg}$ or a Diastolic blood pressure (DBP) of 90mm Hg on both the occasions. All individuals with hypertension (previously known or newly detected) were provided with referrals for physicians available at UPHC, who initiated them with or optimized their anti-hypertensive medication. All cohort members, who completed the two-year follow-up assessment in November-December 2019 are included in the current study.

Procedures: We followed the cohort of individuals with hypertension (previously known or newly detected) for two years. Follow-up was performed using the existing human resources in the public health-delivery system, facilitated by cloud-based data-management tools, and study supervisors. We prepared a list of members of the cohort using Commcare database, and stratified them by cluster. We provided cohort-list of each cluster to respective ASHA, who was responsible for visiting each cohort member at-least once in every three-months, to promote adherence to drug therapies, measurement of blood pressure, and to provide focussed CVD-prevention health education. Monetary incentives were given to ASHAs for every completed follow-up (rupees 50 INR about 1 USD). In each visit, ASHAs recorded linkage to UPHC or a private care provider, and continuation of drug therapy. We defined treatment interruption as failure to obtain a prescription-refill for two-weeks or more after exhaustion of previously obtained drug supplies.

We designed a cloud-based digital tool using CommCare based application to facilitate follow-up. This tool was available on mobile phones of all ASHAs, and in addition to facilitate follow-up, it provided access to baseline values of the participants, and also was to be used for dataentry of each subsequent visit. Study supervisors monitored cohort follow-up using this CommCare based application, and performed additional site-visits for troubleshooting. We also conducted a quarterly-meeting of all ASHAs and study supervisors to monitor follow-ups. A community clinic based one-year adherence assessment was performed by a team of pharmacologists who were trained to assess pill-burden and adherence to previously prescribed therapies. This assessment was limited to those who were on any anti-hypertensive drug therapy in the previous month.

Outcome assessment: Blood pressure control at two-year assessment visit was the key outcome. It was defined as optimally controlled if average SBP was less than 140mm Hg and DBP was less than $90 \mathrm{~mm} \mathrm{Hg}$, and severely uncontrolled if SBP was more than $160 \mathrm{~mm} \mathrm{Hg}$, and DBP more than $100 \mathrm{~mm}$ Hg. This two-year assessment was performed by independent field investigators, who visited households of all participants and measured their blood pressures. Multiple mop-up visits were 
conducted, and facilitation by ASHAs and study supervisors was solicited to improve proportion of follow-ups.

Statistical Analysis: ASHAs and study supervisors entered all study-variables obtained in baseline survey, confirmatory-visits, UPHC-visits, or on follow-up using mobile-phone based data collection system. All the variables were stored on cloud-based CommCare data-management system. The demographic and cardiovascular-risk variables (age, gender, education level, wealth quintiles, tobacco use, alcohol consumption, physical activity levels, body-mass index, waist circumference) were obtained from entries in the baseline questionnaire. History of hypertension obtained at baseline and subsequently obtained SBP and DBP values were used for classification of hypertension status. Primary-care physician consultation decisions culminating in drug escalation, de-escalation or no action, were taken from UPHC visit logs. The distribution of these explanatory variables was compared with respect to outcome, using appropriate tests of significance. The difference was considered as significant if $\mathrm{p}$-value for null hypothesis was less than 0.05 .

We performed a multivariable logistic regression, to evaluate independent risk factors of uncontrolled hypertension. All explanatory variables that were marginally significant on univariate analysis $(\mathrm{p}<0.25)$ were included in the full model. Assumptions for using logistic regression were tested and Hosmer-Lemeshow Goodness-of-fit was also used. All data analysis and visualizations were done using Statistical software $\mathrm{R}^{18}$ and arsenal $^{19}$, finalfit ${ }^{20}$, ggplot ${ }^{21}$, ggpubr $^{22}$, ggstatplot $^{23}$, gtsummary 24 , performance ${ }^{25}$ and tidyverse ${ }^{26}$ packages.

\section{Results}

In November 2017 we initiated a baseline survey in 16 urban slum clusters of Bhopal. Of 6174 individuals surveyed at baseline, we identified a total of 1571 individuals (25.4\%) with hypertension; and all of these were sought to be visited by CHWs once in every two months. A total of 1177 (74.9\%) individuals completed two-year follow up visit done in November-December 2019. Individuals who were lost to follow up were more likely to be men, who were older, and were newly detected with hypertension. (Table S1) Of 1177 individuals who completed follow up, 623 (53\%) knew about their hypertension status at baseline, and 554 (47\%) were newly detected during screening. At baseline, 301 (26\%) individuals were optimally controlled, and at the end of two years their proportion increased to 442 (38\%), an absolute increase of $12 \%$ (95\% CI 10.2-13.9). There was a significant decline of 1.7 (95\% CI -2.9 to -0.5$)$ and $1.7 \mathrm{~mm} \mathrm{Hg}$ (95\% CI (-2.4 to -1.1) in mean SBP and DBP respectively from baseline to follow up. This decline was largely due to reduction in SBP among those with uncontrolled hypertension. (Table 1, Figure 1)

The proportion of individuals with uncontrolled blood pressure was progressively higher in each age band $(55 \%, 63 \%, 67 \%$ and $73 \%$ in those with baseline age of 30-44, 45-59, 60-74, and above 75 years respectively). We observed a significant decline in SBP and DBP, across all age-bands 
of individuals with uncontrolled hypertension at baseline. About $65 \%$ of individuals who were sedentary at baseline, developed uncontrolled hypertension, as compared to only $54 \%$ of those who were non-sedentary. This difference was statistically significant. Individuals who were newly detected to have hypertension, and those who had elevated blood-pressure at baseline, were more likely to be uncontrolled on follow-up. (Table 2, Figure 2)

A total of 699 (59.4\%) individuals were initiated on anti-hypertensive drug therapy, 533 of these were linked to UPHC, and 166 to private-care providers. All of these individuals received follow up visits by ASHAs, and during these visits self-reported adherence to prescribed therapies was similar in both optimally controlled and uncontrolled individuals. (84.4\% vs $85.8 \%$; $\mathrm{p}=0.842$ ) An independent adherence assessment was also done at the end of one-year in 263 of the UPHC attendees, and perceived adherence was lower in those subsequently found to be uncontrolled $(69.5 \%$ vs $79.1 \%$; $\mathrm{p}=0.006$ ). The proportion of individuals who were uncontrolled after two years was significantly higher amongst those who were linked to UPHC as compared to those linked to privateproviders (67\% vs $61 \%$; $\mathrm{p}=0.009)$. Of those linked to UPHC, median number of visits to the facility was similar in optimally controlled and uncontrolled subgroups ( $\mathrm{p}=0.436)$ and $116(21.7 \%)$ individuals had one or more visit culminating in a drug-escalation advise. While 24 (20.6\%) of individuals who were advised drug-escalation were optimally controlled, remaining 92(79\%) were not. Of the 478 of 1177 individuals (40.6\%), defaulted for initiation of drug-therapy, and 276 (58\%) had their blood pressures above 140/90 mm Hg at two-year follow up.

We performed multivariable logistic regression to identify risk-factors for uncontrolled hypertension. Hosmer-Lemeshow goodness-of-fit test was non-significant, there was no multicollinearity, assumptions of homogeneity of variance, residual distribution and absence of influential observations were met, however model's explanatory power was weak (Tjur's R2 $=0.06$, RMSE=0.46). After adjusting for age, and gender newly detected hypertension (OR 2.42 (1.78-3.31)), and BMI (OR 1.04 (1.01-1.07)) were significant independent risk-factors for uncontrolled hypertension. (Table 3) 


\section{Discussion}

In the current study we found that after initial screening and two-year follow-up, about six of every ten individuals with hypertension were on-treatment, and about four were optimally controlled. While overall proportion of individuals with optimally controlled blood-pressure rose over the twoyear period, this modest increase was due to blood-pressure control in less than a-third of newly detected hypertensives. More than two-thirds of the remaining newly detected and about half of previously known hypertensives remained uncontrolled. Those who were uncontrolled, were more likely to be older, had a higher BMI, and were newly detected to have hypertension. These findings demonstrate that obtaining blood-pressure control in vulnerable communities, though feasible is challenging. These findings provide a benchmark for NPCDCS, in terms of achievable goals within short periods of follow-up.

A recent systematic review ${ }^{5}$ reported that in India only $13 \%$ of all individuals with hypertension are treated, and a meagre $8 \%$ are controlled. Our baseline screening bridged the awareness gap, and $\mathrm{CHW}$ based adherence reinforcement improved proportion of on-treatment and controlled individuals to $60 \%$ and $38 \%$ respectively. While these numbers are encouraging, and approach and even exceed proportions for control achieved in previous studies in high-income settings, ${ }^{27,28}$ they bring-forth challenges of initiating anti-hypertensive drugs in all who need them, improving adherence in those initiated, and appropriate dosing requirements. ${ }^{29}$ In the current study education, wealth, or gender did not increase risk of uncontrolled hypertension. These socioeconomic characteristics are perceived as proxy-indicators for awareness, access or empowerment. It is likely that more complex behavioural phenomenon such as fear, reluctance and adverse impact of being labelled with an illness, affected both initiation and adherence to prescribed drug therapies. ${ }^{30}$ Of less than half of all participants who attended UPHC, drug-escalation attempts were no-different in those who were uncontrolled. Therapeutic inertia remains an important physician level barrier to optimal blood pressure control. ${ }^{31} \mathrm{We}$ found that risk of being uncontrolled was consistently higher with increasing age, a factor that contributes to therapeutic inertia. ${ }^{32}$ Further, presence of fixed-dose combinations in the drug formulary in UPHCs could have helped reduce inertia, ${ }^{33}$ as use of combination treatment in newly detected hypertensives is likely to achieve a faster blood-pressure control. $^{27}$

Physical activity is important to achieve blood-pressure control, and is an important component of various population based programs. ${ }^{34}$ Self-reported physical activity levels correlate well with reduced blood pressure levels. ${ }^{35}$ In the current study, hypertensive individuals who reported themselves to be sedentary at baseline were more-likely to be uncontrolled two years later. While this effect observed on univariate analysis, was not significant when adjusted for age and gender, it is an important life-style measure that has a strong legacy effect. ${ }^{36}$ Improved physical activity achieves blood pressure reduction through diverse mechanisms such as reduction in vascular resistance, 
sympathetic activity, inflammation and stress. ${ }^{35}$ It also leads to lower BMI, which was an independent predictor of blood-pressure control in our study. While some studies, such as SPRINT trial have found no relationship between BMI and blood-pressure control ${ }^{37}$, another large study from China found a significant lowering effect. ${ }^{38}$ While mean BMI of participants in SPRINT trial was 29 $\mathrm{kg} / \mathrm{m} 2$, it was $24.4 \mathrm{~kg} / \mathrm{m} 2$ in the Chinese study. Mean BMI of our participants was $25.8 \mathrm{~kg} / \mathrm{m} 2$, closer to that of the Chinese study. It is likely that blood-pressure control in population sub-groups with a lower BMI is more feasible, as compared to those with obesity.

Improving blood pressure control is challenging, and regular follow up with intensive pharmacotherapy is most useful to achieve this goal. In a Cochrane review of 56 randomized control trials, other measures such as self-monitoring, appointment reminders, and health-education had little independent effects and were less useful. ${ }^{39}$ Feasibility of achieving even lower targets than envisaged in NPCDCS, was demonstrated in intensive blood-pressure control arm in SPRINT trial. ${ }^{40}$ Similar intensive management is also possible through CHWs in low-income settings. Two recent trials have demonstrated this effect. First, HOPE4 study demonstrated that CHW based intensive blood pressure control can improve proportion of optimally controlled individuals to $69 \%$ as compared to $30 \%$ in standard care arm. ${ }^{41}$ Second, in another randomized control trial from Argentina, CHW led multidimensional care that involved intensive health-coaching, home BP monitoring, audits and feedbacks optimally controlled $72 \%$ individuals. ${ }^{13}$ When CHWs are provided with intensive supportive supervision, empowered to obtain quick feedbacks on treatment decisions, it can help improve therapeutic inertia and achieve better control levels. ${ }^{42}$

We have established a cohort of individuals with hypertension, with an aim to improve CHW based care delivery in vulnerable populations, and generate evidence that may help implementation of NPCDCS. We used efficient data-management systems, within the programmatic settings to establish a system of community based follow-up. Our study however has had some limitations. We could follow up only three-fourths of our intended cohort, mostly due to migration, and limited availability at home due to long working hours of many participants. Proportion of individuals on-treatment was modest, reflecting the real-world apprehensions many individuals with hypertension have, regarding initiation of drug therapy. Further, the process of obtaining prescription refills from a health-facility often requires missing work on that day, which may not be feasible for the working populations. Last, our follow up duration was only two years. While this is short, but we believe it is sufficient to demonstrate improvements within program settings.

To conclude, newly detected individuals with hypertension, and those who are obese, are two such subgroups that need more intensive monitoring and follow-up to improve optimal control levels in the community. CHWs based follow-ups are feasible, but more intensive treatments and follow-up systems are needed for better blood-pressure control outcomes. 
Acknowledgements- Investigators would like acknowledge efforts of all Community Health Workers (ASHAs) and their officials affiliated to Urban Public Health system in implementing this study.

Conflict of interest - Authors declare no conflict of interest.

Funding- This study was funded by Indian Council of Medical Research, New Delhi as an extramural project grant. Funders have no role in data collection, analysis and writing of the manuscript. (Grant PI- Dr Rajnish Joshi, IRIS-2014-0976)

Ethics approval- The study design was approved by the Institutional Human Ethics Committee of All India Institute of Medical Sciences, Bhopal(Ref: IHEC-LOP/2017/EF00045).

Informed consent- Participant Information Sheet in Hindi language was provided to each participant. All participants provided written informed consent prior to initiation of any study procedures.

Data Statement- Raw data of this study is not deposited in any public repository. However, anonymized raw data of this study would be available to academicians or researchers on reasonable request to corresponding author.

Author contributions: RJ conceived the study; AJ, APP, SA and SK developed the protocol; AL, SKN and NS acquired data, AJ, SA and SK supervised data acquisition, APP, AJ and RJ analysed data and wrote first draft. All authors critically reviewed the first draft and provided inputs for its revisions. 


\section{References}

1. Anchala R, Kannuri NK, Pant H, Khan H, Franco OH, Di Angelantonio E, et al. Hypertension in India: a systematic review and meta-analysis of prevalence, awareness, and control of hypertension. J Hypertens. 2014 Jun;32(6):1170-7.

2. Kokane AM, Joshi R, Kotnis A, Chatterjee A, Yadav K, Revadi G, et al. Descriptive profile of risk factors for cardiovascular diseases using WHO STEP wise approach in Madhya Pradesh. PeerJ. 2020 Aug 6;8:e9568.

3. Kokane AM, Joshi R, Kotnis A, Chatterjee A, Yadav K, Revadi G, et al. Determinants of behavioural and biological risk factors for cardiovascular diseases from state level STEPS survey (2017-19) in Madhya Pradesh. PeerJ. 2020 Dec 10;8:e10476.

4. Gupta R, Gaur K, S Ram CV. Emerging trends in hypertension epidemiology in India. J Hum Hypertens. 2019 Aug;33(8):575-87.

5. Prenissl J, Manne-Goehler J, Jaacks LM, Prabhakaran D, Awasthi A, Bischops AC, et al. Hypertension screening, awareness, treatment, and control in India: A nationally representative cross-sectional study among individuals aged 15 to 49 years. PLOS Medicine. 2019 May 3;16(5):e1002801.

6. Campbell NR, Chockalingam A. Prevention and control of high blood pressure: challenges and opportunities. CMAJ. 1995 Jun 15;152(12):1969-70.

7. Stafford RS. New High Blood Pressure Guidelines: Back on Track With Lower Treatment Goals, but Implementation Challenges Abound. Am J Prev Med. 2018 Oct;55(4):575-8.

8. Thangada ND, Garg N, Pandey A, Kumar N. The Emerging Role of Mobile-Health Applications in the Management of Hypertension. Curr Cardiol Rep. 2018 Jul 26;20(9):78.

9. Xu L, Fang W-Y, Zhu F, Zhang H-G, Liu K. A coordinated PCP-Cardiologist Telemedicine Model (PCTM) in China's community hypertension care: study protocol for a randomized controlled trial. Trials. 2017 May 25;18(1):236.

10. Vedanthan R, Bernabe-Ortiz A, Herasme OI, Joshi R, Lopez-Jaramillo P, Thrift AG, et al. Innovative Approaches to Hypertension Control in Low- and Middle-Income Countries. Cardiol Clin. 2017 Feb;35(1):99-115.

11. R V, Jh K, Ak D, V N, Ca B, Gs B, et al. Community Health Workers Improve Linkage to Hypertension Care in Western Kenya. J Am Coll Cardiol. 2019 Sep 2;74(15):1897-906.

12. Joshi R, Agrawal T, Fathima F, Usha T, Thomas T, Misquith D, et al. Cardiovascular risk factor reduction by community health workers in rural India: A cluster randomized trial. Am Heart J. 2019 Oct;216:9-19.

13. He J, Irazola V, Mills KT, Poggio R, Beratarrechea A, Dolan J, et al. Effect of a Community Health Worker-Led Multicomponent Intervention on Blood Pressure Control in Low-income Patients in Argentina: A Randomized Clinical Trial. JAMA. 2017 Sep 19;318(11):1016-25.

14. Jafar TH, Gandhi M, de Silva HA, Jehan I, Naheed A, Finkelstein EA, et al. A CommunityBased Intervention for Managing Hypertension in Rural South Asia. N Engl J Med. 2020 Feb 20;382(8):717-26. 
15. Neupane D, McLachlan CS, Mishra SR, Olsen MH, Perry HB, Karki A, et al. Effectiveness of a lifestyle intervention led by female community health volunteers versus usual care in blood pressure reduction (COBIN): an open-label, cluster-randomised trial. Lancet Glob Health. 2018;6(1):e66-73.

16. Smolen JR, Wang JJ, Anane SP. Challenges and strategies for hypertension management: qualitative analysis of small primary care practices with varying blood pressure control. Fam Pract. 2019 Oct 8;36(5):644-9.

17. Pakhare AP, Joshi A, Khadanga S, Kumar S, Atal S, Ingle V, et al. Feasibility of Community Health Worker based cardiovascular risk reduction strategies in urban slums of Bhopal: Rationale and design of community based study. medRxiv. 2020 Sep 18;2020.09.18.20189639.

18. R Core Team. R: A Language and Environment for Statistical Computing [Internet]. Vienna, Austria: R Foundation for Statistical Computing; 2019. Available from: https://www.Rproject.org/

19. Heinzen E, Sinnwell J, Atkinson E, Gunderson T, Dougherty G, Votruba P, et al. arsenal: An Arsenal of "R" Functions for Large-Scale Statistical Summaries [Internet]. 2020 [cited 2020 Dec 24]. Available from: https://CRAN.R-project.org/package=arsenal

20. Harrison E, Drake T, Ots R. finalfit: Quickly Create Elegant Regression Results Tables and Plots when Modelling [Internet]. 2020 [cited 2020 Oct 17]. Available from: https://CRAN.Rproject.org/package=finalfit

21. Wickham H, Chang W, Henry L, Pedersen TL, Takahashi K, Wilke C, et al. ggplot2: Create Elegant Data Visualisations Using the Grammar of Graphics [Internet]. 2020 [cited 2020 Oct 17]. Available from: https://CRAN.R-project.org/package=ggplot2

22. Kassambara A. ggpubr: "ggplot2” Based Publication Ready Plots [Internet]. 2020 [cited 2020 Dec 24]. Available from: https://CRAN.R-project.org/package=ggpubr

23. Patil I. ggstatsplot: "ggplot2" Based Plots with Statistical Details [Internet]. 2020 [cited 2020 Dec 24]. Available from: https://CRAN.R-project.org/package=ggstatsplot

24. Sjoberg DD, Curry M, Hannum M, Whiting K, Zabor EC, Drill E, et al. gtsummary: Presentation-Ready Data Summary and Analytic Result Tables [Internet]. 2020 [cited 2020 Oct 17]. Available from: https://CRAN.R-project.org/package=gtsummary

25. easystats/performance [Internet]. easystats; 2020 [cited 2020 Dec 24]. Available from: https://github.com/easystats/performance

26. Wickham H, RStudio. tidyverse: Easily Install and Load the "Tidyverse" [Internet]. 2019 [cited 2020 Oct 19]. Available from: https://CRAN.R-project.org/package=tidyverse

27. Jb B, C Z, Hm T, Dj M, Pj O, Kl M, et al. Combination therapy as initial treatment for newly diagnosed hypertension. Am Heart J. 2011 Jul 18;162(2):340-6.

28. Krousel-Wood M, Muntner P, Carson A, Anderson AH, Delaune E, Cushman WC, et al. Hypertension control among newly treated patients before and after publication of the main ALLHAT results and JNC 7 guidelines. J Clin Hypertens (Greenwich). 2012 May;14(5):27783.

29. Chia YC, Kario K, Turana Y, Nailes J, Tay JC, Siddique S, et al. Target blood pressure and control status in Asia. Journal of Clinical Hypertension. 2020 Mar 1;22(3):344-50. 
30. Marx G, Witte N, Himmel W, Kühnel S, Simmenroth-Nayda A, Koschack J. Accepting the unacceptable: medication adherence and different types of action patterns among patients with high blood pressure. Patient Educ Couns. 2011 Dec;85(3):468-74.

31. Düsing R. Overcoming barriers to effective blood pressure control in patients with hypertension. Curr Med Res Opin. 2006 Aug;22(8):1545-53.

32. Gil-Guillén V, Orozco-Beltrán D, Carratalá-Munuera C, Márquez-Contreras E, Durazo-Arvizu $\mathrm{R}$, Cooper R, et al. Clinical inertia in poorly controlled elderly hypertensive patients: a crosssectional study in Spanish physicians to ascertain reasons for not intensifying treatment. Am J Cardiovasc Drugs. 2013 Jun;13(3):213-9.

33. Mancia G, Rea F, Cuspidi C, Grassi G, Corrao G. Blood pressure control in hypertension. Pros and cons of available treatment strategies. J Hypertens. 2017 Feb;35(2):225-33.

34. Carey RM, Muntner P, Bosworth HB, Whelton PK. Prevention and Control of Hypertension: JACC Health Promotion Series. J Am Coll Cardiol. 2018 Sep 11;72(11):1278-93.

35. Diaz KM, Shimbo D. Physical Activity and the Prevention of Hypertension. Curr Hypertens Rep. 2013 Dec;15(6):659-68.

36. Lee L-L, Watson MC, Mulvaney CA, Tsai C-C, Lo S-F. The effect of walking intervention on blood pressure control: a systematic review. Int J Nurs Stud. 2010 Dec;47(12):1545-61.

37. Oxlund CS, Pareek M, Rasmussen BSB, Vaduganathan M, Biering-Sørensen T, Byrne C, et al. Body Mass Index, Intensive Blood Pressure Management, and Cardiovascular Events in the SPRINT Trial. Am J Med. 2019 Jul;132(7):840-6.

38. Zhang Y-Q, Li Y, Dong Y-G, Wu Y-H, Bian R, Li J-H, et al. A nationwide assessment of blood pressure control and the associated factors in Chinese type 2 diabetes mellitus patients. The Journal of Clinical Hypertension. 2019;21(11):1654-63.

39. Fahey T, Schroeder K, Ebrahim S. Interventions used to improve control of blood pressure in patients with hypertension. Cochrane Database Syst Rev. 2006 Oct 18;(4):CD005182.

40. SPRINT Research Group, Wright JT, Williamson JD, Whelton PK, Snyder JK, Sink KM, et al. A Randomized Trial of Intensive versus Standard Blood-Pressure Control. N Engl J Med. 2015 Nov 26;373(22):2103-16.

41. Schwalm J-D, McCready T, Lopez-Jaramillo P, Yusoff K, Attaran A, Lamelas P, et al. A community-based comprehensive intervention to reduce cardiovascular risk in hypertension (HOPE 4): a cluster-randomised controlled trial. Lancet. 2019 Oct 5;394(10205):1231-42.

42. Long H, Huang W, Zheng P, Li J, Tao S, Tang S, et al. Barriers and Facilitators of Engaging Community Health Workers in Non-Communicable Disease (NCD) Prevention and Control in China: A Systematic Review (2006-2016). Int J Environ Res Public Health. 2018 Oct 26;15(11). 
medRxiv preprint doi: https://doi.org/10.1101/2021.02.02.21251036; this version posted February 5, 2021. The copyright holder for this preprint (which was not certified by peer review) is the author/funder, who has granted medRxiv a license to display the preprint in perpetuity.

It is made available under a CC-BY-NC 4.0 International license .

Table-1: Change in cardiovascular risk factors over two-year follow-up in the cohort $(n=1177)$

\begin{tabular}{|c|c|c|c|c|}
\hline Variables & Baseline (2017) & $\begin{array}{c}\text { Follow Up } \\
\text { (2019) }\end{array}$ & $\begin{array}{c}\text { Absolute } \\
\text { Difference (Cl) }\end{array}$ & p-value \\
\hline \multicolumn{5}{|l|}{ All participants ( $\mathrm{N}=1177)$} \\
\hline SBP (mean, SD) & $146.6(20.6)$ & $145.0(21.2)$ & $-1.7(-2.9$ to -0.5$)$ & 0.007 \\
\hline $\mathrm{DBP}($ mean, SD) & $88.2(12.6)$ & $86.5(12.6)$ & $-1.7(-2.4$ to -1.1$)$ & $<0.001$ \\
\hline Optimal BP control & $301(26 \%)$ & $442(38 \%)$ & $+141(12 \%)$ & $<0.001$ \\
\hline $\mathrm{BMI}($ mean, SD) & $25.7(4.9)$ & $25.8(5.2)$ & $\begin{array}{c}+0.1(-0.05 \text { to } \\
0.18)\end{array}$ & 0.257 \\
\hline Obese or overweight & $536(54 \%)$ & $533(54 \%)$ & $-3(1 \%)$ & 1.000 \\
\hline Waist Circum. (mean, SD) & $89.4(14.4)$ & $92.2(12.2)$ & $2.9(2.3$ to 3.5$)$ & $<0.001$ \\
\hline Abdominal Obesity & $817(79 \%)$ & $868(82 \%)$ & $51(3 \%)$ & 0.0008 \\
\hline \multicolumn{5}{|c|}{ Previously known hypertension at baseline $(\mathrm{N}=623)$} \\
\hline SBP (mean, SD) & $141.8(22.9)$ & $141.6(21.0)$ & $-0.2(-1.9$ to 1.5$)$ & 0.825 \\
\hline $\mathrm{DBP}($ mean, SD) & $84.3(13.4)$ & $83.8(12.3)$ & $-0.5(-1.4$ to 0.5$)$ & 0.316 \\
\hline Optimal BP Control & $301(48 \%)$ & $284(46 \%)$ & $-17(2 \%)$ & 0.277 \\
\hline $\mathrm{BMI}($ mean, SD) & $26.2(4.9)$ & $26.3(5.0)$ & $\begin{array}{c}0.1(-0.05 \text { to } \\
0.26)\end{array}$ & 0.178 \\
\hline Obese or overweight & $320(59 \%)$ & $313(57 \%)$ & $-7(2 \%)$ & 0.371 \\
\hline Waist Circum. (mean, SD) & $89.9(14.8)$ & $93.1(12.3)$ & $3.2(2.3$ to 4.0$)$ & $<0.001$ \\
\hline Abdominal Obesity & $464(85 \%)$ & $488(87 \%)$ & $+22(2 \%)$ & 0.021 \\
\hline \multicolumn{5}{|c|}{ Newly detected hypertension at baseline ( $N=554)$} \\
\hline SBP (mean, SD) & $152.0(16.1)$ & $148.7(20.7)$ & $-3.3(-5.0$ to -1.6$)$ & $<0.001$ \\
\hline $\mathrm{DBP}($ mean, SD) & $92.7(10.1)$ & $89.5(12.3)$ & $\begin{array}{c}-3.2(-4.14 \text { to }- \\
2.2)\end{array}$ & $<0.001$ \\
\hline Optimal BP control & $0(0 \%)$ & $158(29 \%)$ & $+158(29 \%)$ & $<0.001$ \\
\hline $\mathrm{BMI}($ mean, SD) & $25.2(4.9)$ & $25.2(5.4)$ & $\begin{array}{c}0.0(-0.15 \text { to } \\
0.18)\end{array}$ & 0.865 \\
\hline Obese or overweight & $216(48 \%)$ & $220(49 \%)$ & $+4(1 \%)$ & 0.429 \\
\hline Waist Circum. (mean, SD) & $88.7(14.0)$ & $91.3(12.0)$ & $2.6(1.7$ to 3.5$)$ & $<0.001$ \\
\hline Abdominal Obesity & $353(72 \%)$ & $380(76 \%)$ & $+27(4 \%)$ & 0.161 \\
\hline
\end{tabular}


medRxiv preprint doi: https://doi.org/10.1101/2021.02.02.21251036; this version posted February 5, 2021. The copyright holder for this preprint (which was not certified by peer review) is the author/funder, who has granted medRxiv a license to display the preprint in perpetuity.

It is made available under a CC-BY-NC 4.0 International license .

Table-2: Distribution of status of BP control among various socio-demographic, behavioral and biological variables

\begin{tabular}{|c|c|c|c|c|}
\hline \multirow[b]{2}{*}{$\begin{array}{l}\text { Baseline } \\
\text { Characteristics }\end{array}$} & \multirow[b]{2}{*}{$\begin{array}{c}\text { All } \\
N=1,177\end{array}$} & \multicolumn{2}{|c|}{ Blood-pressure outcome after follow-up } & \multirow[b]{2}{*}{ p-value } \\
\hline & & $\begin{array}{c}\text { Optimal control } \\
N=442(38 \%)\end{array}$ & $\begin{array}{l}\text { Not controlled } \\
N=735(62 \%)\end{array}$ & \\
\hline Mean age & $51.7(12.7)$ & $49.9(12.3)$ & $52.9(12.8)$ & $<0.001$ \\
\hline Age Group & & & & $<0.001$ \\
\hline $31-40$ & 284 & $134(47 \%)$ & $150(53 \%)$ & \\
\hline $41-50$ & 347 & $124(36 \%)$ & $223(64 \%)$ & \\
\hline $51-60$ & 272 & $101(37 \%)$ & $171(63 \%)$ & \\
\hline $60+$ & 274 & $83(30 \%)$ & $191(70 \%)$ & \\
\hline Gender & & & & 0.669 \\
\hline Men & 482 & $185(38 \%)$ & $297(62 \%)$ & \\
\hline Women & 695 & $257(37 \%)$ & $438(63 \%)$ & \\
\hline Education & & & & 0.047 \\
\hline Literate & 685 & $274(40 \%)$ & $411(60 \%)$ & \\
\hline Illiterate & 492 & $168(34 \%)$ & $324(66 \%)$ & \\
\hline Wealth Quintiles & & & & 0.641 \\
\hline $\mathrm{Q} 1$ & 148 & 49 (33\%) & 99 (67\%) & \\
\hline Q2 & 179 & $70(39 \%)$ & $109(61 \%)$ & \\
\hline Q3 & 218 & $81(37 \%)$ & $137(63 \%)$ & \\
\hline Q4 & 230 & $93(40 \%)$ & $137(60 \%)$ & \\
\hline Q5 & 332 & $120(36 \%)$ & $212(64 \%)$ & \\
\hline Tobacco & & & & 0.688 \\
\hline Non-user & 725 & $276(38 \%)$ & $449(62 \%)$ & \\
\hline User & 452 & $166(37 \%)$ & $286(63 \%)$ & \\
\hline Alcohol & & & & 0.688 \\
\hline Non-user & 951 & $354(37 \%)$ & $597(63 \%)$ & \\
\hline User & 226 & $88(39 \%)$ & $138(61 \%)$ & \\
\hline Physical Activity & & & & $<0.001$ \\
\hline Non-sedentary & 285 & $131(46 \%)$ & $154(54 \%)$ & \\
\hline Sedentary & 892 & $311(35 \%)$ & $581(65 \%)$ & \\
\hline $\begin{array}{l}\text { Fruits and Vegetables } \\
\text { (Median servings) }\end{array}$ & $1.0(0.5,2.0)$ & $1.0(1.0,2.0)$ & $1.0(0.5,2.0)$ & 0.081 \\
\hline $\begin{array}{l}\text { Mean Salt Intake } \\
\text { (gm/person/day) }\end{array}$ & $8.3(6.7,11.1)$ & $8.3(6.7,11.1)$ & $8.3(6.7,11.1)$ & 0.803 \\
\hline $\begin{array}{l}\text { Mean Edible-oil intake } \\
\text { (ml/person/day) }\end{array}$ & $30.0(25.0,42.0)$ & $30.0(25.7,42.0)$ & $30.0(25.0,42.0)$ & 0.808 \\
\hline Abdominal Obesity & & & & 0.418 \\
\hline Non-obese & 360 & $142(39 \%)$ & $218(61 \%)$ & \\
\hline Obese & 816 & $300(37 \%)$ & $516(63 \%)$ & \\
\hline HTN History & & & & $<0.001$ \\
\hline Newly Detected & 554 & $158(29 \%)$ & $396(71 \%)$ & \\
\hline Past HTN & 623 & $284(46 \%)$ & $339(54 \%)$ & \\
\hline BP Status & & & & $<0.001$ \\
\hline Not controlled & 876 & $245(28 \%)$ & $631(72 \%)$ & \\
\hline Controlled & 301 & $197(65 \%)$ & $104(35 \%)$ & \\
\hline Dysglycemia & & & & 0.417 \\
\hline Absent & 822 & $302(37 \%)$ & $520(63 \%)$ & \\
\hline Present & 355 & $140(39 \%)$ & $215(61 \%)$ & \\
\hline Weight & $62.5(13.6)$ & $61.7(13.6)$ & $62.9(13.6)$ & 0.169 \\
\hline BMI & $25.8(5.2)$ & $25.5(5.3)$ & $26.0(5.2)$ & 0.172 \\
\hline Waist Circumference & $88.9(17.9)$ & $88.6(16.5)$ & $89.1(18.8)$ & 0.376 \\
\hline Random Blood Sugar & $138.2(61.0)$ & $138.1(60.9)$ & $138.3(61.2)$ & 0.696 \\
\hline
\end{tabular}


medRxiv preprint doi: https://doi.org/10.1101/2021.02.02.21251036; this version posted February 5, 2021. The copyright holder for this preprint (which was not certified by peer review) is the author/funder, who has granted medRxiv a license to display the preprint in perpetuity.

\section{It is made available under a CC-BY-NC 4.0 International license .}

Table-3: Logistic regression analysis for determinants of uncontrolled hypertension

\begin{tabular}{|c|c|c|}
\hline Baseline variables & OR (univariable) & OR (multivariable) \\
\hline Age & $1.02(1.01-1.03, \mathrm{p}<0.001)$ & $1.02(1.01-1.04, \mathrm{p}<0.001)$ \\
\hline Women vs Men & $1.06(0.84-1.35, \mathrm{p}=0.625)$ & $0.95(0.69-1.30, \mathrm{p}=0.744)$ \\
\hline Illiterate vs Literate & $1.29(1.01-1.64, \mathrm{p}=0.041)$ & $1.21(0.88-1.65, \mathrm{p}=0.241)$ \\
\hline Tobacco User vs Non-user & $1.06(0.83-1.35, \mathrm{p}=0.643)$ & - \\
\hline Alcohol User vs Non-user & $0.93(0.69-1.26, \mathrm{p}=0.632)$ & - \\
\hline Physical Inactivity vs Non-sedentary & $1.59(1.21-2.08, \mathrm{p}=0.001)$ & $1.44(1.05-1.98, \mathrm{p}=0.024)$ \\
\hline BMI & $1.02(0.99-1.04, \mathrm{p}=0.211)$ & $1.04(1.01-1.07, \mathrm{p}=0.007)$ \\
\hline Waist Circumference & $1.00(0.99-1.01, \mathrm{p}=0.650)$ & - \\
\hline $\begin{array}{l}\text { Newly Detected HTN at baseline vs } \\
\text { Previously known HTN }\end{array}$ & $2.10(1.65-2.68, \mathrm{p}<0.001)$ & $2.38(1.80-3.17, \mathrm{p}<0.001)$ \\
\hline $\begin{array}{l}\text { Dysglycemia at baseline vs No } \\
\text { Dysglycemia }\end{array}$ & $0.89(0.69-1.15, \mathrm{p}=0.381)$ & - \\
\hline
\end{tabular}


medRxiv preprint doi: https://doi.org/10.1101/2021.02.02.21251036; this version posted February 5, 2021. The copyright holder for this preprint (which was not certified by peer review) is the author/funder, who has granted medRxiv a license to display the preprint in perpetuity.

\section{It is made available under a CC-BY-NC 4.0 International license .}

Figure 1: Change in SBP from baseline to follow up by history of hypertension (n=1177)

Change in SBP among newly detected and previously known hypertension groups stratified by BP control status at baseline

Grp: Newly Detected : Uncontrolled

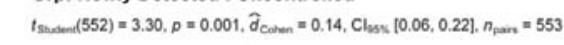

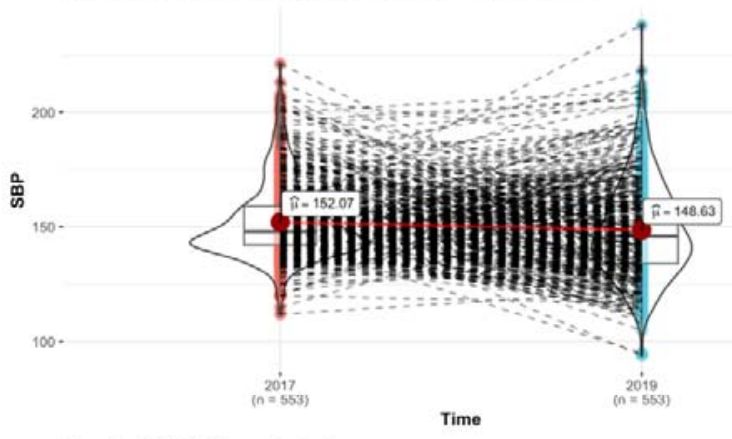

Grp: Past HTN : Uncontrolled

$t_{\text {manden }}(320)=6.91, p=2.7 \mathrm{e}-11, \partial_{\text {conten }}=0.39, \mathrm{Cl}_{905 \mathrm{~s}}\left[0.27,0.501, n_{\text {pand }}=321\right.$

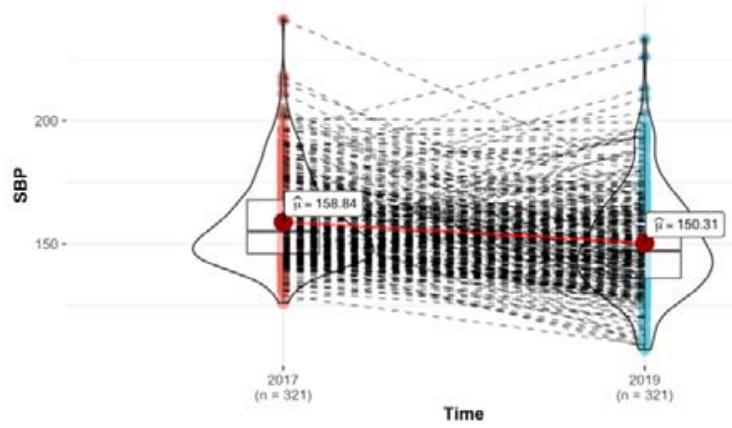

Grp: Past HTN : Controlled

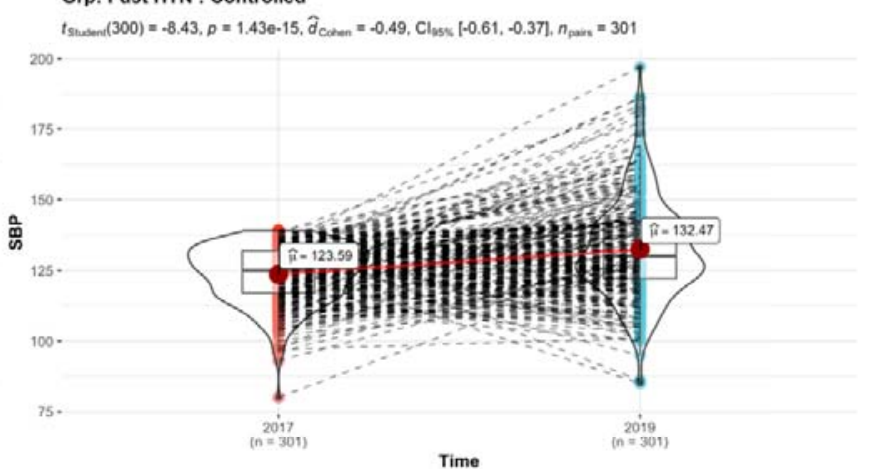

Multi-panel paired box and violin plots showing distribution of Systolic Blood Pressure (SBP) at different time periods. Panels are labelled history of hypertension and status of blood pressure control at 2017. Change in individual's reading is denoted by dotted connecting line. Mean change is indicated by solid red connecting line. 
medRxiv preprint doi: https://doi.org/10.1101/2021.02.02.21251036; this version posted February 5, 2021. The copyright holder for this preprint (which was not certified by peer review) is the author/funder, who has granted medRxiv a license to display the preprint in perpetuity.

It is made available under a CC-BY-NC 4.0 International license .

Figure-2: Change in SBP and DBP in the study population by baseline-BP control status in each age-band.

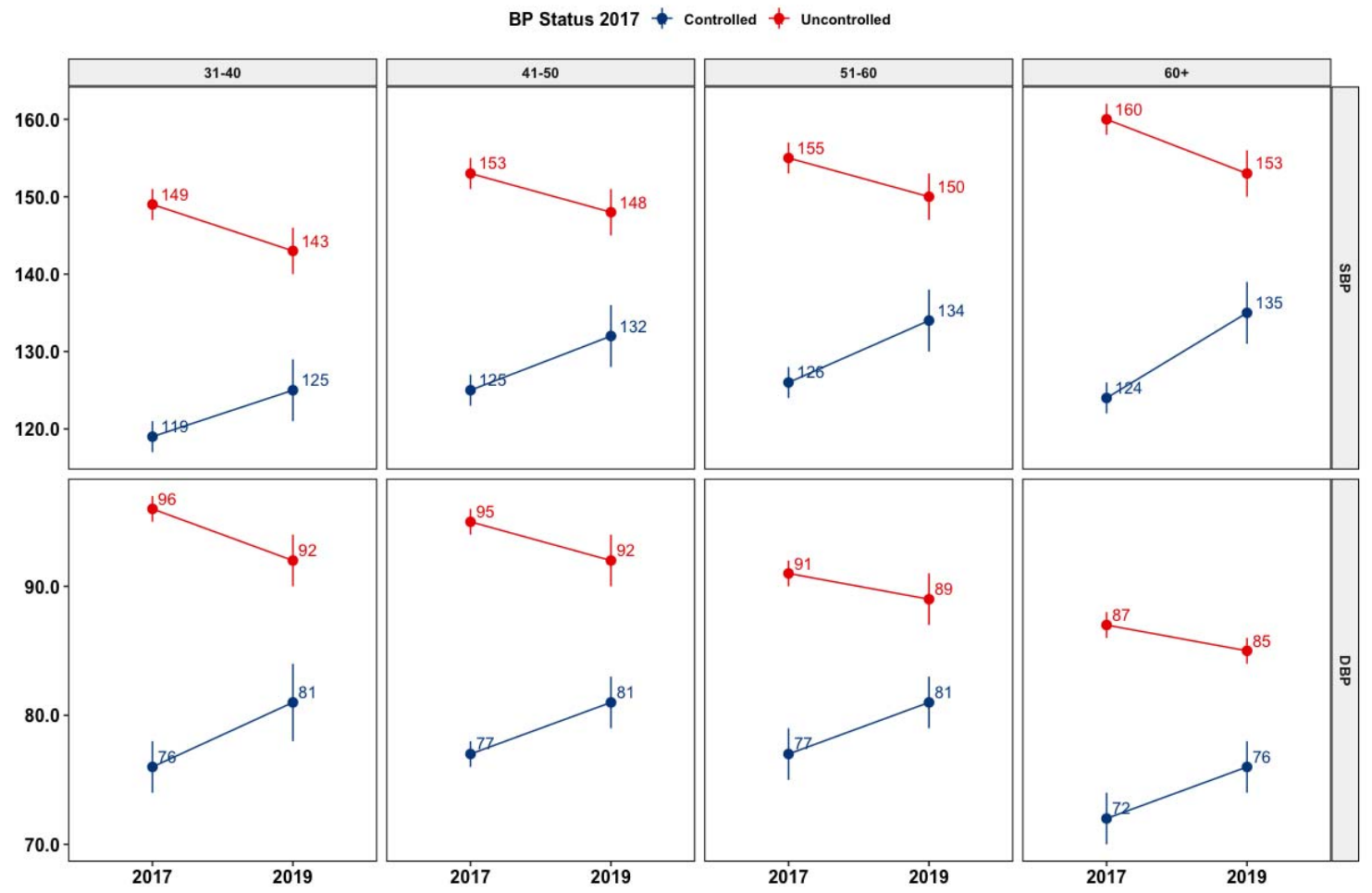

Multi-panel plot showing mean of systolic and diastolic blood pressure recorded in 2017 and 2019. Each panel represents specific age group labelled on top panels and type of blood pressure on extreme right panels. Colour of the joining line indicates status of blood pressure control in 2017. 
medRxiv preprint doi: https://doi.org/10.1101/2021.02.02.21251036; this version posted February 5, 2021. The copyright holder for this preprint (which was not certified by peer review) is the author/funder, who has granted medRxiv a license to display the preprint in perpetuity.

It is made available under a CC-BY-NC 4.0 International license.

Table S1-: Comparison of distribution of socio-demographic variables among those who were followed up and those lost to follow up

\begin{tabular}{|c|c|c|c|c|}
\hline Characteristic & Overall, $\mathrm{N}=1,571$ & Followed, N = $1177(75 \%)$ & Lost to $\mathbf{F} / \mathbf{U}, \mathrm{N}=394(25 \%)$ & p-value \\
\hline Age & $52.1(13.3)$ & $51.7(12.7)$ & $53.3(15.0)$ & 0.154 \\
\hline Gender & & & & $<0.001$ \\
\hline Men & $687(44 \%)$ & $482(41 \%)$ & $205(52 \%)$ & \\
\hline Women & $884(56 \%)$ & $695(59 \%)$ & $189(48 \%)$ & \\
\hline Education & & & & 0.955 \\
\hline Literate & $913(58 \%)$ & $685(58 \%)$ & $228(58 \%)$ & \\
\hline Illiterate & $658(42 \%)$ & $492(42 \%)$ & $166(42 \%)$ & \\
\hline Wealth Quintiles & & & & 0.689 \\
\hline Q1 & $199(14 \%)$ & $148(13 \%)$ & $51(15 \%)$ & \\
\hline Q2 & $236(16 \%)$ & $179(16 \%)$ & $57(16 \%)$ & \\
\hline Q3 & $276(19 \%)$ & $218(20 \%)$ & $58(17 \%)$ & \\
\hline Q4 & $310(21 \%)$ & $230(21 \%)$ & $80(23 \%)$ & \\
\hline Q5 & $434(30 \%)$ & $332(30 \%)$ & $102(29 \%)$ & \\
\hline BMI & $25.7(5.2)$ & $25.8(5.2)$ & $25.2(5.3)$ & 0.111 \\
\hline Waist Circumference & $88.8(17.3)$ & $88.9(17.9)$ & $88.4(15.1)$ & 0.443 \\
\hline Physical Activity & & & & 0.271 \\
\hline Non-sedentary & $392(25 \%)$ & $285(24 \%)$ & $107(27 \%)$ & \\
\hline Sedentary & $1,179(75 \%)$ & $892(76 \%)$ & $287(73 \%)$ & \\
\hline Abdominal Obesity & & & & 0.036 \\
\hline Non-obese & $503(32 \%)$ & $360(31 \%)$ & $143(36 \%)$ & \\
\hline Obese & $1,065(68 \%)$ & $816(69 \%)$ & $249(64 \%)$ & \\
\hline Alcohol & & & & 0.203 \\
\hline Non-user & $1,257(80 \%)$ & $951(81 \%)$ & $306(78 \%)$ & \\
\hline User & $314(20 \%)$ & $226(19 \%)$ & $88(22 \%)$ & \\
\hline Tobacco & & & & 0.004 \\
\hline Non-user & $935(60 \%)$ & $725(62 \%)$ & $210(53 \%)$ & \\
\hline User & $636(40 \%)$ & $452(38 \%)$ & $184(47 \%)$ & \\
\hline Dysglycemia 2017 & & & & 0.020 \\
\hline Absent & $1,122(71 \%)$ & $822(70 \%)$ & $300(76 \%)$ & \\
\hline Present & $449(29 \%)$ & $355(30 \%)$ & $94(24 \%)$ & \\
\hline HTN History & & & & $<0.001$ \\
\hline Newly Detected & $813(52 \%)$ & $554(47 \%)$ & $259(66 \%)$ & \\
\hline Past HTN & $758(48 \%)$ & $623(53 \%)$ & $135(34 \%)$ & \\
\hline
\end{tabular}


medRxiv preprint doi: https://doi.org/10.1101/2021.02.02.21251036; this version posted February 5, 2021. The copyright holder for this preprint (which was not certified by peer review) is the author/funder, who has granted medRxiv a license to display the preprint in perpetuity.

It is made available under a CC-BY-NC 4.0 International license.

Table-S2: Distribution of Health-care seeking pattern and adherence to drug therapy by blood pressure control outcome as determined on follow-up $(n=1177)$

\begin{tabular}{|c|c|c|c|c|}
\hline Characteristic & $\begin{array}{l}\text { Overall, } N= \\
1,177\end{array}$ & $\begin{array}{l}\text { Optimal, } N=442 \\
(38 \%)\end{array}$ & $\begin{array}{l}\text { Not controlled, } N=735 \\
(62 \%)\end{array}$ & $\begin{array}{l}\text { p- } \\
\text { value }\end{array}$ \\
\hline \multicolumn{5}{|l|}{ Facility linkage for Drug therapy } \\
\hline Govt Facility (UPHC) & 533 & $176(33 \%)$ & $357(67 \%)$ & \multirow{3}{*}{0.009} \\
\hline Private Facility & 166 & $64(39 \%)$ & $102(61 \%)$ & \\
\hline Neither & 478 & $202(42 \%)$ & $276(58 \%)$ & \\
\hline \multicolumn{5}{|l|}{ Visit log at UPHC } \\
\hline Number of visits (Median, IQR) & $2.0(1.0,9.2)$ & $3.0(1.0,10.0)$ & $2.0(1.0,9.0)$ & 0.436 \\
\hline Visits resulting in drug escalation & $0.0(0.0,1.0)$ & $0.0(0.0,0.0)$ & $0.0(0.0,1.0)$ & 0.042 \\
\hline Participants with drug escalation & 116 & $24(21 \%)$ & $92(79 \%)$ & 0.097 \\
\hline \multicolumn{5}{|l|}{ Follow up by ASHAs } \\
\hline Directly followed-up by ASHA & 928 & $348(38 \%)$ & $580(62 \%)$ & 0.999 \\
\hline Perceived Adherence (100) & $85.3(29.5)$ & $84.4(30.9)$ & $85.8(28.6)$ & 0.842 \\
\hline \multicolumn{5}{|c|}{ Independent adherence assessment in a sample of those on regular therapy } \\
\hline Number & 263 & 78 & 185 & \\
\hline Pill Burden (Daily) & $2.6(2.2)$ & $2.6(2.4)$ & $2.6(2.1)$ & 0.660 \\
\hline Perceived Adherence (100) & $72.3(36.5)$ & $79.1(34.5)$ & $69.5(37.1)$ & 0.006 \\
\hline
\end{tabular}

